\title{
Development of Strategies to Promote Circular Economy in the Management of Construction and Demolition Waste: A Case Study in Manaus, Brazil
}

Maria do Perpétuo Socorro Lamego Oliveira

Universidade Fernando Pessoa

Evailton Arantes de Oliveira

Universidade Fernando Pessoa

Ana Fonseca ( $\nabla$ afonseca@ufp.edu.pt )

Universidade Fernando Pessoa https://orcid.org/0000-0002-3207-4819

\section{Research Article}

Keywords: Construction and Demolition Waste, Circular Economy, Amazon Region, Environmental Management, Construction Industry, Environmental Surveillance

Posted Date: May 26th, 2021

DOI: https://doi.org/10.21203/rs.3.rs-551958/v1

License: (c) (i) This work is licensed under a Creative Commons Attribution 4.0 International License. Read Full License 


\section{Abstract}

Construction and Demolition Waste (CDW) cause environmental impacts in a worldwide scale. The existing international concern regarding the adequate management of CDW is justified by the large amount of this waste produced in a daily basis, together with its potential hazardous effects on ecosystems and human health. In countries with growing economies, like Brazil, it is of the utmost importance to promote sustainability-oriented practices that can co-exist with economic development. In this scope, the present research proposes strategies regarding the management of CDW based on the Circular Economy principles, focusing the case study of the municipality of Manaus, in the centre of the Amazon Forest. The characterization of the reference situation regarding CDW management in Manaus revealed several deficiencies, namely the lack of reuse and recycling opportunities, the unsupervised disposal of CDW in illegal landfills, together with insufficient surveillance procedures and inadequate policies from regional authorities like the Manaus City Hall and the Amazon's Regional Council of Engineering and Agronomy (CREA-AM). The acknowledgement of these problems led to the identification of improvement opportunities and to the development and operationalization of Circular Economy promotion strategies: valorisation of CDW through the enhancement of reuse and recycling opportunities, operationalized through a mobile phone application; inclusion of sensibilization and surveillance practices regarding professional activities related to CDW management on the CREA-AM inspection plan; and the proposal of alterations in the municipal policies regarding CDW disposal in the public landfill. These strategies have been implemented in the Manaus municipality, but are easily adaptable to other Brazilian municipalities and even to other countries' realities.

\section{Introduction}

Inadequate management of construction and demolition waste (CDW) is a worldwide environmental problem that has been increasing over the years due to the growth of the construction industry in developed and developing countries. It is widely recognized that the generation of CDW is a consequence of economic and social development, since these wastes are a subproduct of urban lifestyle (Mesjaszlech 2014; Aslam et al. 2020; Li et al. 2020b), and therefore the adequate disposal of CDW is an important challenge of modern urban management.

The amount of CDW generated and the correspondent management practices differ from country to country, depending on the existing policies, regulations, and waste disposal infrastructures (Blaisi 2019; Li et al. 2020b; Lv et al. 2020). For example, Singapore reports a 99\% recycling rate regarding CDW, while China only recycles $5 \%$ of the estimated 2,36 billion tons of CDW produced in a year (Lv et al. 2020); in Europe the amount of CDW produced is over 870 million tons per year (Bonoli and Zanni 2021), with recovery rates around 90\% (European Commission 2020); the Environmental Protection Agency of the United States of America reports 600 million tons of CDW produced in 2018, 24\% of which have their final disposal in landfills (U.S. EPA 2020); in Brazil the amount of CDW generated in 2019 is estimated as 44,5 million ton (ABRELP 2020), but the recycling practices for CDW in Brazil are scarce (Contreras et al. 2016; Paz et al. 2018, 2020; Oliveira et al. 2019a). 
As waste material produced in the process of construction, renovation or demolition of structures, CDW mainly consists of concrete, bricks, asphalt, excavated soil, metals, wood, ceramics, plastics, glass and cardboard (Yeheyis et al. 2013; Ossa et al. 2016; Cai and Waldmann 2019; Oliveira et al. 2019a).

Hazardous substances may be found in CDW, like oil, paints, solvents and wood preservatives, as well as toxic materials resulting from demolition works, like for example asbestos and polychlorinated biphenyls (PCB) (Esa et al. 2017). Therefore, the inadequate handling and disposal of CDW can cause several negative environmental impacts, such as soil and water contamination, proliferation of plagues and diseases' transmission vectors (like insects and rats), landscape degradation, and obstruction of rivers and other drainage channels (Yeheyis et al. 2013; Blaisi 2019; Paz et al. 2020).

Linear based practices using the model "extract-produce-consume-dispose" are still the dominant rule in the construction industry (Esa et al. 2017; Ogunmakinde et al. 2021), in spite of the widely demonstrated economic and environmental benefits of CDW reuse and recycling. Based on the principles of Circular Economy, CDW reduction, reuse and recycling practices have relevant impacts on the amount of disposed waste, and at the same time contribute to preserve the natural resources used as raw material in the construction industry (Yeheyis et al. 2013; Contreras et al. 2016; Ossa et al. 2016). Therefore, there is a high potential to apply Circular Economy principles to CDW management (Adams et al. 2017; GálvezMartos et al. 2018; Mhatre et al. 2021; Ogunmakinde et al. 2021; Singh et al. 2021).

The focus of the present study is the municipality of Manaus (Amazonas-Brazil), located in the centre of the Amazon Forest, with more than 2 million inhabitants and a rising construction industry. Clandestine illegal landfills are common in the outskirts of Manaus, and are considered a low-cost solution for the disposal of CDW as an alternative to the disposal in the city's official landfill complex. These clandestine landfills lack environmental professionals to supervise the mitigation of the negative environmental impacts caused, and in addition, no inspection from competent government sectors occurs in these sites. Therefore, the current situation regarding CDW management and disposal in Manaus is harmful for the environment, negatively affects the ecosystem of the Amazon region, and has direct negative impacts on public health.

In this context, the present research aims to develop and operationalize new strategies to improve the management of CDW in the municipality of Manaus, involving different stakeholders in the public and private sectors. To achieve the research goal, literature has been reviewed in order to understand the state of the art regarding circular economy principles applied to the management of CDW. A detailed analysis of the current practices for CDW management in the municipality of Manaus has been performed, enabling the identification of improvement opportunities. New strategies have been defined and operationalized to reduce the environmental burden caused by CDW, benefiting the residents of Manaus and contributing to the preservation of the Amazon.

\title{
Literature Review
}

\author{
Circular Economy
}


The concept of Circular Economy (CE), introduced by Boulding (1966) and complemented by Pearce and Turner (1990), defends the need for the establishment of closed-loop resource systems (Boulding 1966; Pearce and Turner 1990). Counteracting on traditional linear production and consumption practices, CE defends industrial models that are restorative by design, where materials are recovered and reused instead of being discarded as waste (Smol et al. 2017; Fiksel et al. 2020).

CE is based on the following principles (Adams et al. 2017; Smol et al. 2017):

- To preserve natural resources by increasing materials' productivity.

- To increase or maintain the value of materials and to circulate them at the highest utility, thus eliminating (or at least minimising) waste.

- To re-design production systems to enhance closed-loop processes regarding material and energy flows.

Pursuing these goals, CE models are supported by concepts like Industrial Ecology, reverse logistics, cradle-to-cradle design, eco-efficiency, and the $3 \mathrm{R}$ hierarchy for waste management - reduce, reuse, recycle (Fiksel et al. 2020; Ogunmakinde et al. 2021).

Considering that there is a relevant number of waste streams that are presently underutilized (Fiksel et al. 2020), the promotion of CE-based business models could result in considerable economic and environmental benefits: conservation of natural resources, economic valorisation of waste, opportunities for new economic activities with job creation, reduction in energy consumption and consequentially in greenhouse gas emissions, besides the avoidance of costs and environmental burdens associated with waste treatment (Smol et al. 2017; Ogunmakinde et al. 2021). Also, by reducing dependence on scarce resources and long-distance supply chains, CE enhances business and community resilience (Fiksel et al. 2020).

Many countries have introduced CE principles in their policies and legislations - e.g. China, Japan, United Kingdom and all the countries belonging to the European Union (Smol et al. 2017). However, the implementation of $\mathrm{CE}$ in different industrial sectors has followed diverse approaches, and the lack of common strategies and instruments has limited the desired widespread of CE (Singh et al. 2021).

Modern technological tools have a fundamental role in the support of CE strategies: digital networks and intelligent robotics are frequently used in waste management processes, like for example sensor-based infrastructures for waste collection, digital image analysis and robotics for waste separation, geographic information systems and global positioning system to assist waste disposal, and data sharing technologies to support product lifecycle analysis (Paz et al. 2018; Esmaeilian et al. 2018; Sarc et al. 2019; Kabirifar et al. 2020; Li et al. 2020a; Lv et al. 2020; Yu et al. 2021).

With significant impacts on the consumption of raw materials and on waste production, CE is crucial for the promotion of Sustainable Development strategies (Lin 2020). In fact, CE enables economic growth without increasing resources' consumption, and is a concept that implies the redesign of industrial 
systems, and deep transformations on production chains and consumption habits. Thus, CE strategies are clearly aligned with the United Nations Sustainable Development Goals (United Nations 2015), specially with Goal 8 - Promote sustained, inclusive and sustainable economic growth, full and productive employment and decent work for all , Goal 9 - Build resilient infrastructure, promote inclusive and sustainable industrialization and foster innovation and Goal 12 - Ensure sustainable consumption and production patterns.

\section{Circular Economy applied to CDW management}

An industry with high material intensity like construction can achieve considerable economic and environmental benefits by increasing material efficiency through the adoption of CE strategies. In what concerns CDW management, CE relies upon the 3Rs principles: promote waste reduction opportunities, and enhance reuse and recycle to close material loops.

$\mathrm{CDW}$ reduction is the waste management option having the least negative environmental impacts, therefore it should be the highest priority in waste management plans. CDW reduction is highly dependent on strategies developed in the design stage to enhance resource efficiency. For example, the use of prefabricated modules can reduce CDW by $80 \%$ (Gálvez-Martos et al. 2018), among other strategies that could have relevant impacts on waste reduction like Building Information Modelling (BIM) (Yeheyis et al. 2013; Huang et al. 2018; Cai and Waldmann 2019; Li et al. 2020a) and lean construction (Kabirifar et al. 2020; Osobajo et al. 2020). However, effective CDW reduction is conditioned by the lack of design standards focusing waste reduction and by the lack of awareness among architects and engineers regarding waste reduction opportunities in the design phase (Huang et al. 2018; Kabirifar et al. 2020).

Reuse of CDW consists in using building materials more than once, either in their original function or considering a different purpose. This implies effective CDW collection and sorting practices, which may be difficult to operationalize due to lack of knowledge and technical equipment regarding waste sorting at the source, and lack of space to store separated waste. Also, the lack of formal criteria to assure the quality of reused building materials affects consumers' quality perceptions, and are therefore major drawbacks for CDW reusing practices (Huang et al. 2018; He and Yuan 2020; Cristiano et al. 2021). Nevertheless, several studies defend that adopting effective material reuse practices is an essential pathway to the success of the construction industry (Osobajo et al. 2020).

CDW has significant recycling potential: metallic waste, clay, glass and wood are valuable materials, and concrete and ceramic waste can be recycled as aggregates that may be used to produce new concrete and asphalt (Yeheyis et al. 2013; Bonoli and Zanni 2021). However, CDW recycling requires adequate waste collection and sorting technologies, and often the high cost of the recycling techniques decreases the price advantage of recycled material when compared to original materials (Gálvez-Martos et al. 2018; Huang et al. 2018). Also, effective recycling of CDW requires the existence of an organized market for secondary materials to uptake recycled waste (Gálvez-Martos et al. 2018; Singh et al. 2021). 
Several authors have studied best practices and improvement opportunities regarding CDW management strategies in the different phases of the construction and demolition process. Table 1 presents a summary of the main results obtained from these studies. Nevertheless, the results of the implementation of these strategies are beyond expectations, mainly due to the inadequate understanding of the following key factors: regulatory framework (obligation), stakeholders' attitudes (who), CDW life-cycle design (when) and CDW management tools (how) (Kabirifar et al. 2020).

Table 1 - Best practices for CDW reduction, reuse and recycling 
Pre-construction / pre-demolition phase

Best practices

- To foster offsite construction: use prefabricated elements, precast beams, modern methods of construction, rental and re-use of auxiliaries;

- To maximize the recovery of materials in end-of-life stages: limited number of different materials and components; use of easy-to-separate materials; standard sizes;

- To adequately plan on-site waste management: identify all potential waste and define specific actions for every type of waste produced, including re-use and recycling opportunities;

- To assure the existence of all the required technical equipment for effective waste management;

- To train and educate the construction workforce regarding effective ways to minimize waste generation;

- To adequately plan supply chain management in order to control material stocks.

Construction / Demolition phase

Best practices

- To separate and process mono-fractional waste streams whenever possible;

- To avoid material loss by adequate logistics, promoting adequate material storage and handling practices;

- To promote reverse logistics and other business-tobusiness schemes;

- To use selective building deconstruction;

- To supervise the adequate application of the waste management plan;

- To monitor on-site and off-site waste sorting practices;

- To assure the adequate handling and maintenance of technical equipment required in waste management operations;

- To assure the adequate storage of waste in order to avoid material degradation;

- To assure safe transport of waste, including preventive measures for potential environmental hazards
Referred by

(Yeheyis et al. 2013; Esa et al. 2017; Gálvez-Martos et al. 2018; Cai and Waldmann 2019; Kabirifar et al. 2020; Osobajo et al. 2020)
(Yeheyis et al. 2013; Esa et al. 2017; Gálvez-Martos et al. 2018; Cai and Waldmann 2019; Kabirifar et al. 2020; Ogunmakinde et al. 2021) 


\section{Policies for the promotion of CE-based practices in CDW management}

Local and central administration policies have a relevant role in the promotion of Circular Economy principles in CDW management practices. Gálvez-Martos et al. (2018) defend that public authorities, at the national and local levels, should: develop CDW management plans prioritizing waste reduction and reuse and fostering innovation regarding recycling opportunities; define standards or regulations for onsite management of every type of waste; and promote the definition of quality assurance schemes regarding recycled products. These authors also refer the importance of using economic instruments to enhance the performance of waste management systems (landfill taxes, recycling subsidies and refunds).

Li et al. (2020b) identified nine policy instruments with potential to foster the CDW recycling industry, and used regression analysis to explore the relation between these policies and the development of the CDW recycling industry in 52 Chinese cities. Their results indicate landfill disposal taxes had the most effective results in the Chinese context, followed by the creation of quality labels and quality standards for recycled materials (Li et al. 2020b).

In this scope, Jia et al. (2018), using dynamic simulation and decision analysis techniques, concluded that a combination of policies including penalties for inadequate waste disposal, subsidies for waste recycling, and fees for waste discharging, would greatly reduce the amount of CDW disposed in illegal damps (Jia et al. 2018).

Ajayi and Oyedele (2017) defend that adequate legislation and fiscal policies are crucial for CDW minimisation, namely the inclusion of tax benefits and incentives to good performers, and the requirement to use proven waste efficient design, procurement and construction methods. These authors also highlight the importance of the following enablers and facilitators to corroborate policy requirements - adequate information regarding the quality, availability and benefits of secondary materials; and adequate markets to provide access to recycled materials (Ajayi and Oyedele 2017).

Yu et al. (2021) highlight the importance of CE promoting policies in the construction industry, namely the definition of strict waste classifications on-site to promote reuse and recyclability, the promotion of information-sharing technologies to enhance communication between different stakeholders, and the creation of financial incentives for innovation and circular business models (Yu et al. 2021).

\section{Analysis of the current practices for CDW management in Manaus}

The city of Manaus is located in the North of Brazil, in the centre of the Amazon Forest. With a territorial area of $11400 \mathrm{~km}^{2}$, Manaus has a growing population (Fig. 1) which is presently around 2220000 
inhabitants. This population growth resulted in increasing demands for housing and infrastructures, and consequently the construction industry in Manaus has doubled in the last decade, reaching 1700 registered construction companies in 2018 (Brazilian Institute of Geography and Statistics 2020).

According to official data from the Manaus City Hall (Manaus Urban Cleaning Department 2020), the average rate of Municipal Solid Waste (MSW) collected in Manaus in 2020 was 1,083 kg per capita, from which only $2,2 \%$ were recycled. The main destination of these solid waste is the municipal landfill, under the direct management of the Manaus City Hall. With a total area of 66 ha, this public landfill received 967277 ton of waste during 2019 (Manaus Urban Cleaning Department 2021), and its lifetime expectancy has been decreasing over the years due to the rise in waste production.

The Urban Cleaning Department of Manaus is also responsible for the collection of waste from illegal dumps - over 144000 ton collected in 2019 - and from the margins and riverbeds of the urban streams belonging to Manaus' watershed - 29,3 ton of waste collected daily in 2020 (Manaus Urban Cleaning Department 2020). These numbers demonstrate the existing practices of waste deposition in inadequate and illegal places in Manaus.

In what concerns $\mathrm{CDW}$, Brazilian legislation stipulates that the responsibility for its adequate disposal belongs to the waste producers. In the municipality of Manaus, the only available legal solution for CDW disposal is the municipal landfill. However, high deposition costs are applied, and therefore construction companies tend to outsource the transport and disposal of their CDW to private companies operating in this area (Oliveira et al. 2019a).

As reported by Oliveira et al. (2021b), the majority of these outsourced companies lack environmental permits and do not have the adequate technical qualifications to prevent environmental hazards in the CDW management process. Therefore, inadequate CDW management practices are occurring in Manaus, including the use of illegal clandestine landfills for CDW disposal (Oliveira et al. 2021a).

The inadequate disposal of CDW in unprepared places currently occurring in Manaus has substantial negative impacts, described in Table 2.

Table 2 Impacts of inadequate CDW management practices occurring in Manaus 


\begin{tabular}{|c|c|c|c|c|}
\hline \multirow{2}{*}{$\begin{array}{l}\text { Inadequate CDW } \\
\text { management } \\
\text { practices }\end{array}$} & \multicolumn{4}{|l|}{ Negative Impacts } \\
\hline & Urban & Environmental & Social & Economic \\
\hline \multirow[t]{2}{*}{$\begin{array}{l}\text { Lack of CDW } \\
\text { selective sorting } \\
\text { and valorisation }\end{array}$} & & $\begin{array}{l}\text { Loss of reuse } \\
\text { and recycling } \\
\text { opportunities }\end{array}$ & $\begin{array}{l}\text { Decrease in the } \\
\text { useful lifetime of } \\
\text { the public landfill }\end{array}$ & $\begin{array}{l}\text { Loss of } \\
\text { economic value } \\
\text { from material } \\
\text { with reuse and } \\
\text { recycling } \\
\text { potential }\end{array}$ \\
\hline & & $\begin{array}{l}\text { Overcharging } \\
\text { of public } \\
\text { landfills }\end{array}$ & $\begin{array}{l}\text { Loss of job } \\
\text { opportunities in } \\
\text { the waste sorting } \\
\text { and valorisation } \\
\text { areas }\end{array}$ & \\
\hline \multirow{4}{*}{$\begin{array}{l}\text { CDW disposal in } \\
\text { inadequate } \\
\text { places inside the } \\
\text { city }\end{array}$} & $\begin{array}{l}\text { Destruction of } \\
\text { sidewalks }\end{array}$ & $\begin{array}{l}\text { Dust } \\
\text { emissions }\end{array}$ & Traffic accidents & \\
\hline & $\begin{array}{l}\text { Creation of obstacles } \\
\text { for pedestrians }\end{array}$ & $\begin{array}{l}\text { Visual } \\
\text { impacts }\end{array}$ & $\begin{array}{l}\text { Proliferation of } \\
\text { diseases }\end{array}$ & $\begin{array}{l}\text { Road and } \\
\text { sidewalks } \\
\text { reparation } \\
\text { costs }\end{array}$ \\
\hline & Road obstruction & Noise & $\begin{array}{l}\text { Injuries for } \\
\text { pedestrians }\end{array}$ & $\begin{array}{l}\text { Gutter } \\
\text { unclogging } \\
\text { costs }\end{array}$ \\
\hline & Clogging of gutters & $\begin{array}{l}\text { Attraction of } \\
\text { insects and } \\
\text { rats }\end{array}$ & & \\
\hline \multirow[t]{4}{*}{$\begin{array}{l}\text { CDW disposal in } \\
\text { illegal landfills }\end{array}$} & $\begin{array}{l}\text { Floods caused by the } \\
\text { accumulation of } \\
\text { waste in the margins } \\
\text { and riverbeds of } \\
\text { urban streams }\end{array}$ & $\begin{array}{l}\text { Soil } \\
\text { contamination }\end{array}$ & $\begin{array}{l}\text { Proliferation of } \\
\text { diseases }\end{array}$ & $\begin{array}{l}\text { Illegal landfills } \\
\text { removal and } \\
\text { cleaning costs }\end{array}$ \\
\hline & & $\begin{array}{l}\text { Water } \\
\text { pollution }\end{array}$ & & $\begin{array}{l}\text { Flood } \\
\text { reparation } \\
\text { costs }\end{array}$ \\
\hline & & $\begin{array}{l}\text { Visual } \\
\text { impacts }\end{array}$ & & \\
\hline & & $\begin{array}{l}\text { Ecosystem } \\
\text { disturbance } \\
\text { and } \\
\text { biodiversity } \\
\text { loss }\end{array}$ & & \\
\hline $\begin{array}{l}\text { CDW } \\
\text { management } \\
\text { companies not } \\
\text { registered in }\end{array}$ & & $\begin{array}{l}\text { Lack of } \\
\text { technical } \\
\text { skills to } \\
\text { prevent }\end{array}$ & $\begin{array}{l}\text { Lack of } \\
\text { surveillance in } \\
\text { the operations of } \\
\text { CDW collection, }\end{array}$ & $\begin{array}{l}\text { Loss of } \\
\text { opportunities } \\
\text { for tax and } \\
\text { fines collection }\end{array}$ \\
\hline
\end{tabular}


Oliveira et al. (2019a) studied the waste management practices regarding the CDW produced in construction works developed in 2018 by three major construction industries operating in Manaus, corresponding to over $90000 \mathrm{~m}^{2}$ of constructed area. Wood, paper/cardboard and debris (concrete, bricks and ceramics) represent the majority of the CDW produced in the construction works under analysis. These construction companies refer very high costs with CDW management - only metal waste is sold for recycling purposes, and the transport and disposal of other produced waste is outsourced to private companies. Wood and paper/cardboard waste, produced in high quantities in these industries and having high reuse and recycling potential, are not being valorised due to the lack of an organized system for waste commercialization (Oliveira et al. 2019a).

The role of regional administration authorities in the CDW management process in Manaus has also been studied through the analysis of the actions promoted and the results obtained by the Regional Council of Engineering and Agronomy of the state of Amazonas (CREA-AM) (Oliveira et al. 2021b). This regional administration body is responsible for the supervision of technical professions to prevent inadequate practices and has, since 2017, an Inspection and Surveillance Plan for the Civil Engineering Chamber focusing professionals and companies in the construction industry area. The analysis of the records of inadequate practices regarding the construction industry and CDW management companies during 2017 and 2018 led to the conclusion that the major irregularities detected were related with the lack of adequate company's licencing procedures and with the development of activities without the supervision of technicians duly registered in CREA-AM. In what concerns the records existing in CREA-AM regarding the activities of environmental professionals in CDW management, a significant decrease was verified from 2017 to 2018 (Fig. 2). These results demonstrate that construction activities in Manaus are being performed without the adequate support of skilled professionals to mitigate the negative environmental impacts associated with CDW, highlighting the need to increase educational and surveillance actions directed both to technicians and construction industries (Oliveira et al. 2021b).

\section{Identification and operationalization of improvement strategies}

The analysis of the current practices of CDW management in Manaus described in the previous section highlights the following existing problems:

- There are very little reuse and recycling opportunities regarding CDW;

- Construction industries are not hiring environmental technicians to support the management of the produced CDW; 
- Construction industries and CDW management companies are using illegal landfills to dispose waste;

- Most companies operating in the CDW management, transport and disposal areas do not have the required technical skills to prevent environmental burdens;

- The public landfill does not have the necessary infrastructures to promote the reuse and recycling of CDW;

- The surveillance of regional administration bodies is not effective in the prevention of inadequate practices from construction industries and CDW management companies.

In this context, improvement opportunities have been identified, at the light of the Circular Economy principles referred in the Literature Review section. Different stakeholders have been considered in the establishment and operationalization of the improvement strategies, considering that the successful implementation of Circular Economy projects in the construction industry requires de adequate engagement of different actors (Adams et al. 2017; Gálvez-Martos et al. 2018; Mak et al. 2019).

The proposed improvement strategies regarding CDW management in Manaus are summarized in Fig. 3, and are described in the following sections.

\section{Promotion of CDW valorisation opportunities}

To operationalize the principles of Circular Economy, it is imperative to promote an organized market to promote reuse and recycling opportunities for the CDW produced in Manaus. Through an organized market for CDW it would be possible to commercialize, exchange or donate sub-products of construction with value for other industries. This requires the creation of adequate communication channels involving construction professionals, waste management companies, recycling industries, among other stakeholders with potential interest in recycling or reusing CDW. For this purpose the use of new technologies is highly recommended (Lv et al. 2020; Yu et al. 2021).

Under this premise, the operationalization of an organized market for CDW reuse and recycling in Manaus was enhanced through the development of a mobile app (Oliveira et al. 2019b). Focusing the disclosure of reuse and recycling opportunities for the most common CDW produced in Manaus, this tool can be used by construction professionals and even common citizens who need to dispose construction waste from private construction works (Fig. 4). Waste disposal companies can also be an important user of this mobile app tool, since it can be used to advertise their services regarding the different disposal options. Since it is aimed to promote good practices in CDW management, the mobile app includes the possibility of tracking and inspecting the disposal of CDW by citizens, companies and public sectors responsible for inspection in the environmental area. Therefore, only companies dully registered and legalized can access the mobile app for advertisement purposes, and all information regarding the destination of the waste transacted through the mobile app must be communicated. 
The adequate use of this mobile app tool requires its potential users to have high awareness levels regarding CDW management options, including the environmental and social impacts of inadequate practices. This can be achieved through education and training programs. A few pilot tests have already been performed, and the interest and acceptability levels associated with the mobile app tool were very high among construction professionals and common citizens (Oliveira et al. 2019b).

Revision of the policies regarding the public landfill of Manaus

The presently occurring overload of the capacity of Manaus' public landfill is unsustainable, and measures should be promoted to effectively reduce the amount of waste disposed in this landfill, specially focusing waste with reuse and recycling potential.

On the other hand, the promotion of CDW disposal in the public landfill is important to assure that all necessary precautions are being taken regarding the prevention of environmental hazards - which do not occur when CDW disposal is performed in illegal dumps. The promotion of the public landfill as a legal and safe disposal option for CDW could be made through the definition of adequate disposal fees. The definition of the fees applied to CDW disposal in the public landfill must consider the balance between low-cost options, which would be inefficient in the promotion of reduction opportunities, and high-cost options that would enhance the use of illegal dumps (Huang et al. 2018; Cristiano et al. 2021).

In this context, the following measures have been proposed to the Manaus City Hall, the entity responsible for the management of the public landfill:

1. to install equipment for adequately sorting the CDW received in the public landfill, therefore enabling materials reuse and recycling;

2. to install equipment for crushing $\mathrm{CDW}$, reducing its volume and promoting its safe and costly transport to recycling facilities;

3. to promote the donation, sale or exchange of the material with reuse and recycling potential using the mobile app tool developed on the scope of the present study; and

4. to implement tax favouring policies for companies that promote reduce, reuse and recycling practices regarding $\mathrm{CDW}$.

\section{Improvement of surveillance practices}

Current surveillance practices regarding CDW management in Manaus are not being effective, as demonstrated in the previous section. Regional administration bodies like CREA-AM can have a relevant role in the promotion of adequate practices for CDW management and disposal (Oliveira et al. 2021b), either through the definition and operationalization of adequate surveillance plans, as well as through the promotion of awareness and education among technical professionals and construction industries (Kabirifar et al. 2020). 
In this scope, alterations were proposed to the existing Inspection and Surveillance Plan for the Civil Engineering Chamber of CREA-AM, and are expected to be operationalized in the biennium 2021-2022. The alterations proposed aim to intensify the surveillance on CDW management, transport, disposal and treatment practices, specifically focusing:

- the registration and GPS tracking of all CDW collection boxes that are stored in construction sites;

- the verification of compliance regarding the existence of legal permits / legal registration for all companies operating with CDW management, transport and disposal;

- the surveillance of clandestine landfills used to dispose CDW; and

- the supervision of technical activity registration processes to ensure that the necessary technical environmental support is being provided.

It must be highlighted that CREA-AM surveillance activities should be complemented with environmental education actions to promote adequate waste management procedures in construction sites, enhancing the existing options regarding construction waste materials reuse and recycling.

\section{Conclusion}

The analysis of the current practices of CDW production, management and disposal in the municipality of Manaus revealed several deficiencies that are affecting the Amazonian ecosystem and the health of the population: due to the lack of recycling and reuse opportunities for CDW, these wastes are being disposed in illegal and clandestine landfills, and the surveillance of local administration bodies is not enough to assure the minimization of the corresponding negative environmental impacts.

The acknowledgement of these problems and the understanding of their causes led to the identification of important improvement opportunities, considering the Circular Economy principles applied to the construction industry analysed in the literature review. The following strategic measures were identified and operationalized:

i. Promotion of CDW reuse and recycling practices, operationalized through the elaboration of a mobile phone application promoting good practices for exchanging, donating, selling and disposing of CDW;

ii. Promotion of awareness, education and training sessions for technical professionals and construction industries regarding adequate CDW management practices to prevent environmental impacts;

iii. Improvement of the role of local administration bodies regarding the prevention of inadequate practices among technical professionals and companies operating in the construction area, operationalized through the updating of the CREA-AM Inspection and Surveillance Plan, to enhance the adequate environmental surveillance of landfills used for CDW disposal, including GPS tracking of CDW collection boxes; and

iv. Adaptation of the regional public policies to promote the adequate management of CDW, proposed to the Manaus City Hall in the scope of the management of the Manaus Landfill Complex. 
The operationalization of the strategies developed within this research are expected to result in the reduction of the amount of CDW produced - due to the reuse and recycling opportunities identified and operationalized - and in the promotion of adequate CDW disposal practices - due to the improvement of policies and surveillance practices from regional authorities. These are the main contributions of the present research, which are expected to lead to an important reduction of the negative environmental impacts caused by the inadequate disposal of CDW presently occurring in Manaus.

The new CDW management strategies developed within the scope of this research were based on the case study of the municipality of Manaus, but are extendable to any other municipality in Brazil or in other developing countries. Thus, it is hoped to contribute to foster the principles of the Circular Economy in Brazil, which are currently taking their first steps, but are essential for the promotion of Sustainability that brings co-existence between economic, social and environmental growth.

\section{Declarations}

\section{Funding}

No funding was received for conducting this study.

\section{Conflicts of interest/Competing interests}

The authors have no conflicts of interest to declare that are relevant to the content of this article.

Availability of data and material (data transparency)

Data sharing not applicable to this article as no datasets were generated or analysed during the current study.

\section{Authors' contributions}

All authors contributed to the study conception and design. Material preparation, data collection and analysis were performed by Maria do Perpétuo Socorro Lamego Oliveira, with the support of the other authors. The first draft of the manuscript was written by Ana Margarida Fonseca and all authors commented on previous versions of the manuscript. All authors read and approved the final manuscript.

\section{References}

1. ABRELP (2020) Solid waste in Brazil (in Portuguese). https://abrelpe.org.br/panorama-2020/. Accessed 10 Dec 2020

2. Adams KT, Osmani M, Thorpe T, Thornback J (2017) Circular economy in construction: Current awareness, challenges and enablers. Proc Inst Civ Eng Waste Resour Manag 170:15-24. https://doi.org/10.1680/jwarm.16.00011 
3. Ajayi SO, Oyedele LO (2017) Policy imperatives for diverting construction waste from landfill: Experts' recommendations for UK policy expansion. J Clean Prod 147:57-65.

https://doi.org/10.1016/j.jclepro.2017.01.075

4. Aslam MS, Huang B, Cui L (2020) Review of construction and demolition waste management in China and USA. J Environ Manage 264:110445. https://doi.org/10.1016/j.jenvman.2020.110445

5. Blaisi NI (2019) Construction and demolition waste management in Saudi Arabia: Current practice and roadmap for sustainable management. J Clean Prod 221:167-175.

https://doi.org/10.1016/j.jclepro.2019.02.264

6. Bonoli A, Zanni S (2021) Sustainability in Building and Construction within the Framework of Circular Cities and European New Green Deal . The Contribution of Concrete Recycling. Sustainability 13:2139

7. Boulding KE (1966) The economics of the coming spaceship earth. In: Jarret $H$ (ed) Environmental quality in a growing economy. The Johns Hopkins University Press, Baltimore

8. Brazilian Institute of Geography and Statistics (2020) Construction Industry in Brazil. https://www.ibge.gov.br/estatisticas/economicas/industria/9018-pesquisa-anual-da-industria-daconstrucao.html?=\&t=downloads. Accessed 15 Oct 2020

9. Brazilian Institute of Geography and Statistics (2021) Cities and States: Manaus. https://www.ibge.gov.br/cidades-e-estados/am/manaus.html. Accessed 29 Mar 2021

10. Cai G, Waldmann D (2019) A material and component bank to facilitate material recycling and component reuse for a sustainable construction: concept and preliminary study. Clean Technol Environ Policy 21:2015-2032. https://doi.org/10.1007/s10098-019-01758-1

11. Contreras M, Teixeira SR, Lucas MC, et al (2016) Recycling of construction and demolition waste for producing new construction material (Brazil case-study ). Constr Build Mater 123:594-600. https://doi.org/10.1016/j.conbuildmat.2016.07.044

12. Cristiano S, Ghisellini P, D'Ambrosio G, et al (2021) Construction and demolition waste in the Metropolitan City of Naples, Italy: State of the art, circular design, and sustainable planning opportunities. J Clean Prod 293:. https://doi.org/10.1016/j.jclepro.2021.125856

13. Esa MR, Halog A, Rigamonti L (2017) Developing strategies for managing construction and demolition wastes in Malaysia based on the concept of circular economy. J Mater Cycles Waste Manag 19:1144-1154. https://doi.org/10.1007/s10163-016-0516-x

14. Esmaeilian B, Wang B, Lewis $K$, et al (2018) The future of waste management in smart and sustainable cities: A review and concept paper. Waste Manag. 81:177-195

15. European Commission (2020) Recovery rate of construction and demolition waste. https://ec.europa.eu/eurostat/databrowser/view/cei_wm040/default/table?lang=en. Accessed 28 Dec 2020

16. Fiksel J, Sanjay P, Raman K (2020) Steps toward a resilient circular economy in India. Clean Technol Environ Policy. https://doi.org/10.1007/s10098-020-01982-0 
17. Gálvez-Martos JL, Styles D, Schoenberger H, Zeschmar-Lahl B (2018) Construction and demolition waste best management practice in Europe. Resour Conserv Recycl 136:166-178. https://doi.org/10.1016/j.resconrec.2018.04.016

18. He L, Yuan H (2020) Investigation of construction waste recycling decisions by considering consumers' quality perceptions. J Clean Prod 259:120928. https://doi.org/10.1016/j.jclepro.2020.120928

19. Huang B, Wang $X$, Kua $H$, et al (2018) Construction and demolition waste management in China through the 3R principle. Resour Conserv Recycl 129:36-44. https://doi.org/10.1016/j.resconrec.2017.09.029

20. Jia S, Liu X, Yan G (2018) Dynamic analysis of construction and demolition waste management model based on system dynamics and grey model approach. Clean Technol Environ Policy 20:20892107. https://doi.org/10.1007/s10098-018-1594-3

21. Kabirifar K, Mojtahedi M, Wang C, Tam VWY (2020) Construction and demolition waste management contributing factors coupled with reduce, reuse, and recycle strategies for effective waste management: A review. J Clean Prod 263:121265. https://doi.org/10.1016/j.jclepro.2020.121265

22. Li CZ, Zhao Y, Xiao B, et al (2020a) Research trend of the application of information technologies in construction and demolition waste management. J Clean Prod 263:. https://doi.org/10.1016/j.jclepro.2020.121458

23. Li J, Yao Y, Zuo J, Li J (2020b) Key policies to the development of construction and demolition waste recycling industry in China. Waste Manag 108:137-143. https://doi.org/10.1016/j.wasman.2020.04.016

24. Lin BC (2020) Sustainable Growth: A Circular Economy Perspective. J Econ Issues 54:465-471. https://doi.org/10.1080/00213624.2020.1752542

25. Lv H, Li Y, Yan H Bin, et al (2020) Examining construction waste management policies in mainland China for potential performance improvements. Clean Technol Environ Policy. https://doi.org/10.1007/s10098-020-01984-y

26. Mak TMW, Yu IKM, Wang L, et al (2019) Extended theory of planned behaviour for promoting construction waste recycling in Hong Kong. Waste Manag 83:161-170. https://doi.org/10.1016/j.wasman.2018.11.016

27. Manaus Urban Cleaning Department (2020) Management Report 2013-2020 (in Portuguese). https://semulsp.manaus.am.gov.br/wp-content/uploads/2020/12/Relatorio-Semulsp-2013-a-2020parcial.pdf. Accessed 30 Mar 2021

28. Manaus Urban Cleaning Department (2021) Manaus Municipal Landfill. https://semulsp.manaus.am.gov.br/aterro-sanitario/. Accessed 30 Mar 2021

29. Mesjasz-lech A (2014) Municipal waste management in context of sustainable urban development. Procedia - Soc Behav Sci 151:244-256. https://doi.org/10.1016/j.sbspro.2014.10.023

30. Mhatre P, Gedam V, Unnikrishnan S, Verma S (2021) Circular economy in built environment Literature review and theory development. J Build Eng 35:. 
https://doi.org/10.1016/j.jobe.2020.101995

31. Ogunmakinde OE, Sher W, Egbelakin T (2021) Circular economy pillars: a semi - systematic review. Clean Technol Environ Policy. https://doi.org/10.1007/s10098-020-02012-9

32. Oliveira MS, Oliveira EA, Fonseca AM (2021a) Actions To Inhibit Environmental Impacts on Clandestine Landfills in the Amazon. Procedia Environ Sci Eng Manag 8:407-415

33. Oliveira MS, Oliveira EA, Fonseca AM (2021b) The Role of Regional Administration on the Promotion of Social Responsibility Practices: A Case Study in the Amazon Region. In: Leal Filho, W.; Tortato, U.; Frankenberger $F($ ed) Integrating Social Responsibility and Sustainable Development - Addressing Challenges and Creating Opportunities. Springer International Publishing

34. Oliveira MS, Oliveira EA, Freitas RR, et al (2019a) Waste Management at Construction Sites in the Municipality of Manaus, Amazonas, Brazil: Characterization of the Current Situation. Curr World Environ 14:326-335. https://doi.org/10.12944/cwe.14.2.17

35. Oliveira MS, Oliveira EA, Wanderley A, et al (2019b) Smart management of waste from construction sites: mobile application technology in the city Manaus, Amazonas, Brazil. In: XIII CTV 2019 Proceedings: XIII International Conference on Virtual City and Territory: "Challenges and paradigms of the contemporary city". Barcelona, pp 8426-8440

36. Osobajo OA, Oke A, Omotayo T, Obi LI (2020) A systematic review of circular economy research in the construction industry. Smart Sustain Built Environ. https://doi.org/10.1108/SASBE-04-2020-0034

37. Ossa A, García JL, Botero E (2016) Use of recycled construction and demolition waste ( CDW ) aggregates: A sustainable alternative for the pavement construction industry. J Clean Prod 135:379386. https://doi.org/10.1016/j.jclepro.2016.06.088

38. Paz DHF da, Lafayette KPV, Sobral M do C (2018) GIS-based planning system for managing the flow of construction and demolition waste in Brazil. Waste Manag Res 36:541-549. https://doi.org/10.1177/0734242X18772096

39. Paz DH, Lafayette KP, Holanda MJ, et al (2020) Assessment of environmental impact risks arising from the illegal dumping of construction waste in Brazil. Environ Dev Sustain 22:2289-2304. https://doi.org/10.1007/s10668-018-0289-6

40. Pearce DW, Turner RK (1990) Economics of Natural Resources and the Environment. The Johns Hopkins University Press, Baltimore

41. Sarc R, Curtis A, Kandlbauer L, et al (2019) Digitalisation and intelligent robotics in value chain of circular economy oriented waste management - A review. Waste Manag. 95:476-492

42. Singh S, Babbitt C, Gaustad G, et al (2021) Thematic exploration of sectoral and cross-cutting challenges to circular economy implementation. Clean Technol Environ Policy. https://doi.org/10.1007/s10098-020-02016-5

43. Smol M, Kulczycka J, Avdiushchenko A (2017) Circular economy indicators in relation to ecoinnovation in European regions. Clean Technol Environ Policy 19:669-678. https://doi.org/10.1007/s10098-016-1323-8 
44. U.S. EPA (2020) Construction and Demolition Debris: Material-Specific Data. https://www.epa.gov/facts-and-figures-about-materials-waste-and-recycling/construction-anddemolition-debris-material. Accessed 28 Dec 2020

45. United Nations (2015) Transforming our world: the 2030 agenda for sustainable development. https://sdgs.un.org/sites/default/files/publications/21252030 Agenda for Sustainable Development web.pdf. Accessed 12 Jul 2020

46. Yeheyis M, Hewage K, Alam MS, et al (2013) An overview of construction and demolition waste management in Canada: A lifecycle analysis approach to sustainability. Clean Technol Environ Policy 15:81-91. https://doi.org/10.1007/s10098-012-0481-6

47. Yu Y, Murat D, Bhochhibhoya S, Volker L (2021) Towards Circular Economy through Industrial Symbiosis in the Dutch construction industry: A case of recycled concrete aggregates. J Clean Prod 293:126083. https://doi.org/10.1016/j.jclepro.2021.126083

\section{Figures}

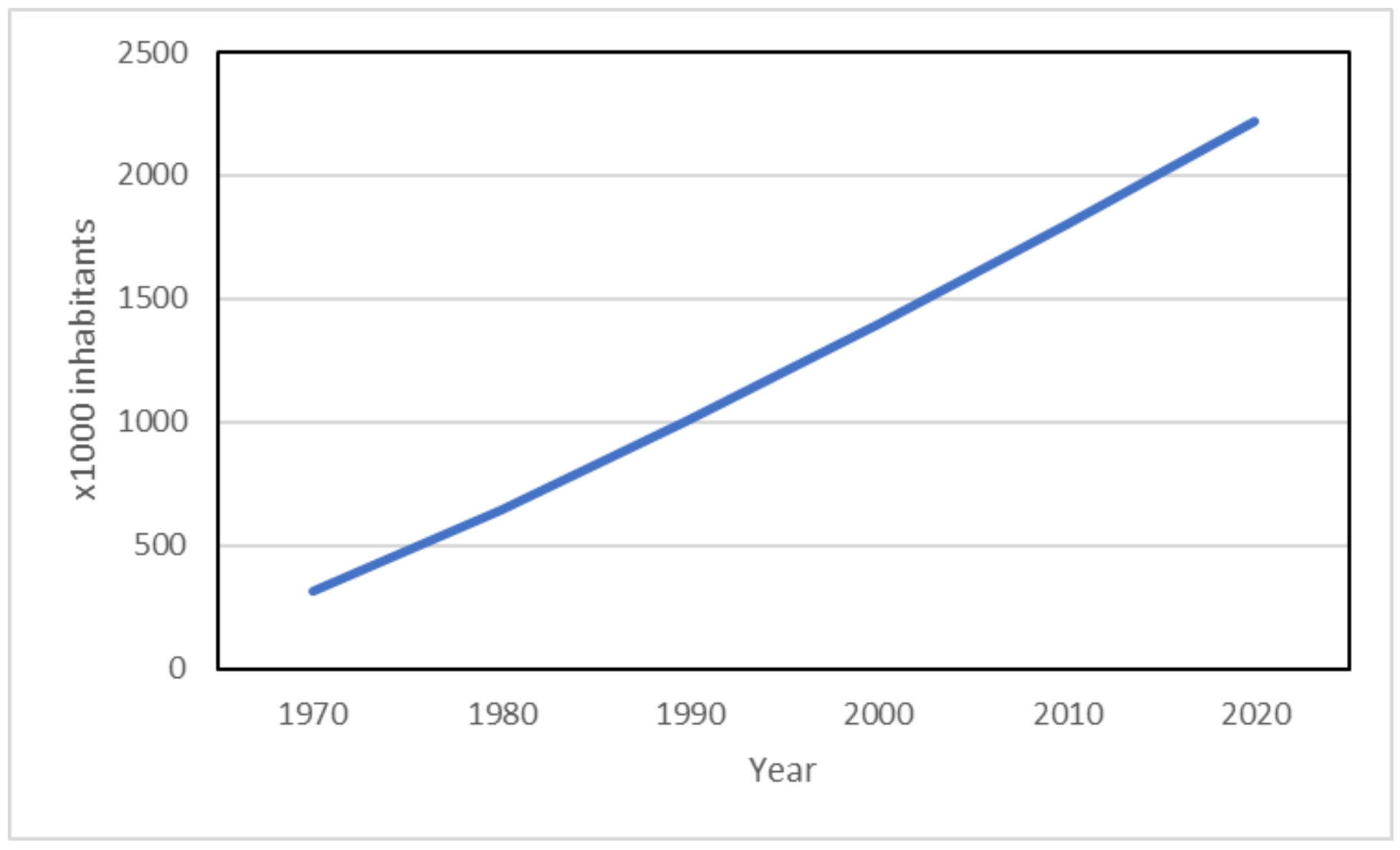

\section{Figure 1}

Evolution of Manaus population (Brazilian Institute of Geography and Statistics 2021) 


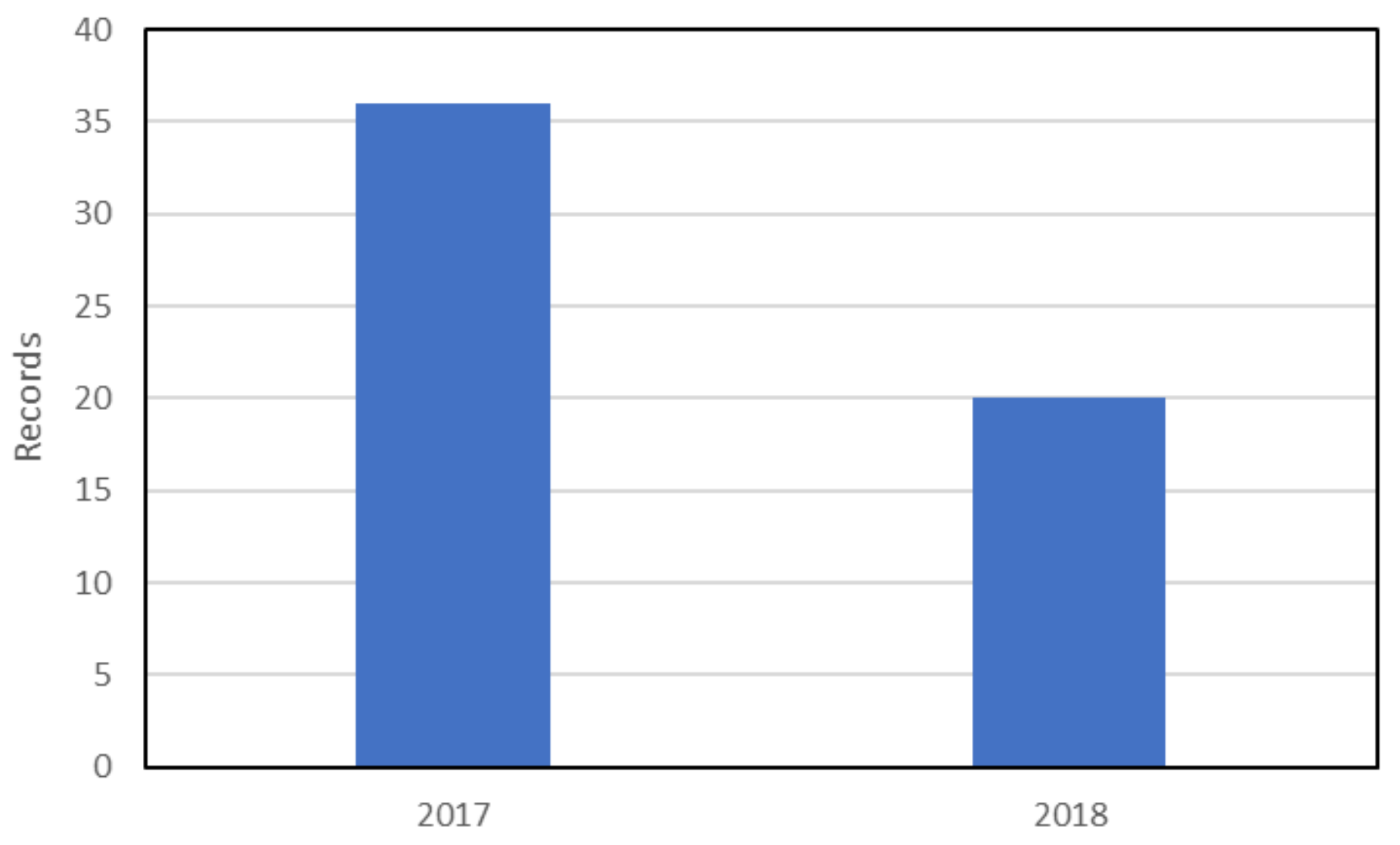

Figure 2

Number of CREA-AM records regarding the activities of environmental professionals in CDW management (adapted from Oliveira et al. 2021b) 


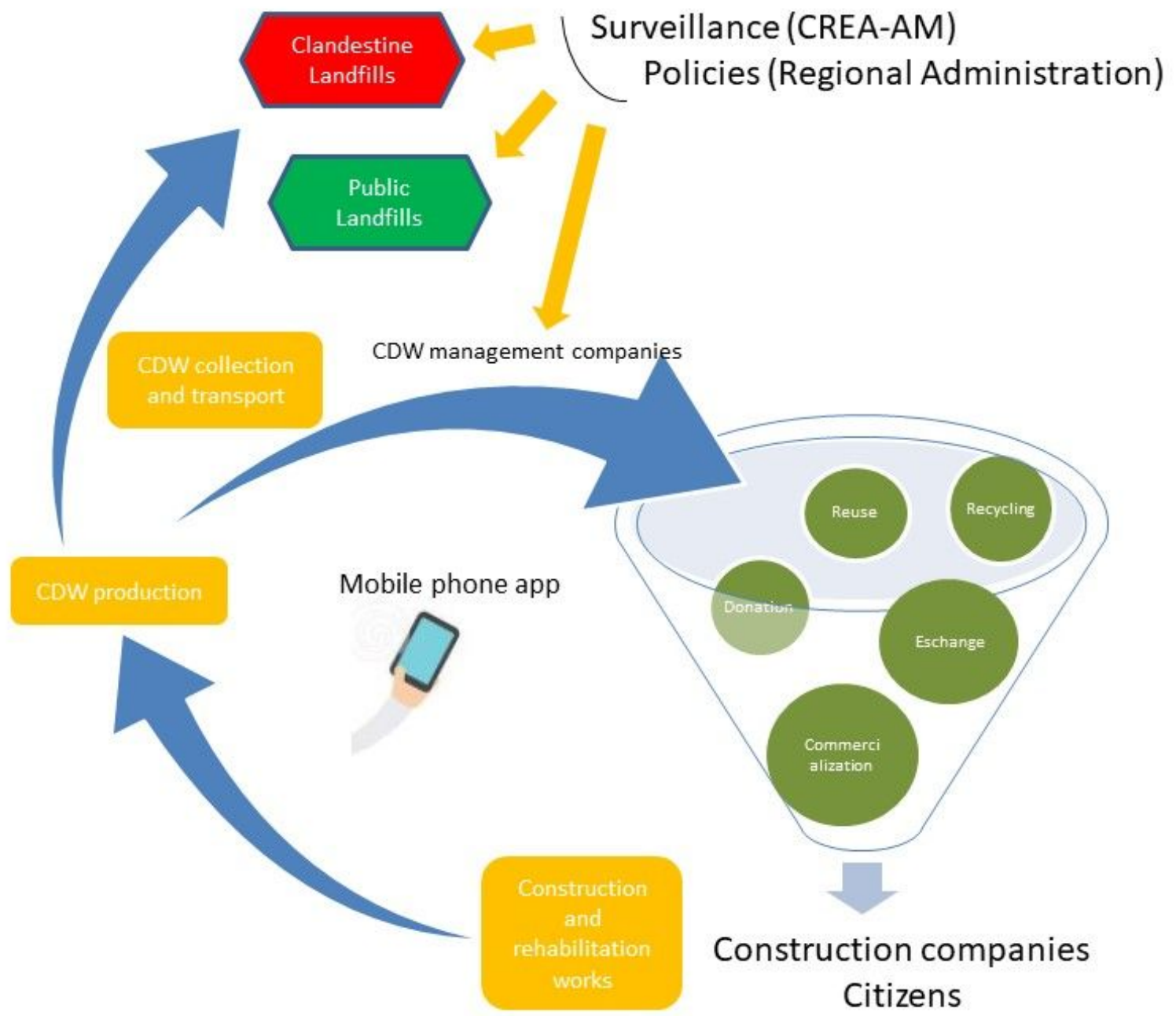

Figure 3

Improvement strategies regarding CDW management in Manaus 


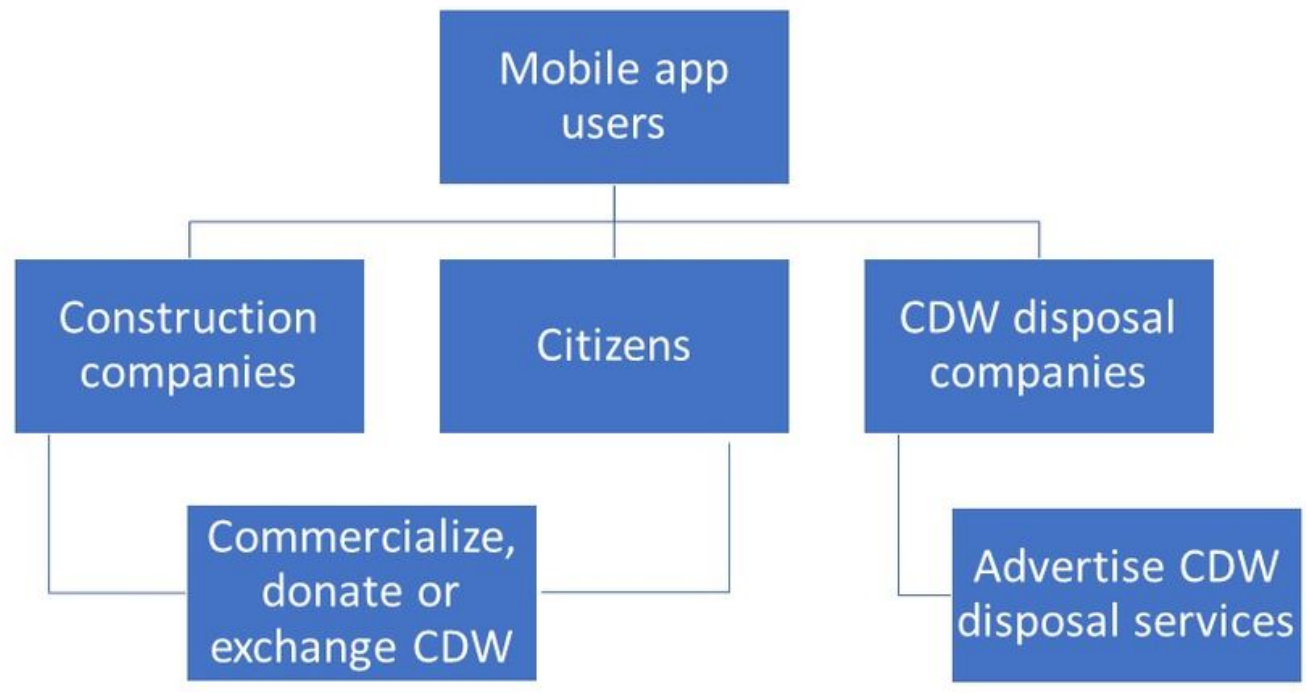

\section{Figure 4}

Mobile app functions for different types of users (adapted from Oliveira et al. 2019b)

\section{Supplementary Files}

This is a list of supplementary files associated with this preprint. Click to download.

- GraphicalAbstract.pptx 